

\title{
Passive infrared thermography measurement of transverse cracking evolution in cross-ply laminates
}

Julien Berthe, Matthieu Ragonet

\section{To cite this version:}

Julien Berthe, Matthieu Ragonet. Passive infrared thermography measurement of transverse cracking evolution in cross-ply laminates. Strain, 2021, 10.1111/str.12293 . hal-02267352

HAL Id: hal-02267352

https://hal.science/hal-02267352

Submitted on 2 Nov 2021

HAL is a multi-disciplinary open access archive for the deposit and dissemination of scientific research documents, whether they are published or not. The documents may come from teaching and research institutions in France or abroad, or from public or private research centers.
L'archive ouverte pluridisciplinaire HAL, est destinée au dépôt et à la diffusion de documents scientifiques de niveau recherche, publiés ou non, émanant des établissements d'enseignement et de recherche français ou étrangers, des laboratoires publics ou privés.

\section{(c)(1)}

Distributed under a Creative Commons Attribution| 4.0 International License 


\title{
Passive infrared thermography measurement of transverse cracking evolution in cross-ply laminates
}

\author{
J. Berthe(i) | M. Ragonet
}

DMAS, ONERA, Lille, France

Correspondence

J. Berthe, DMAS, ONERA, F-59014 Lille,

France.

Email: julien.berthe@onera.fr

\begin{abstract}
Over the last decades, various experimental methodologies have been used to study the matrix crack density evolution in cross-ply laminates. The main drawback of these techniques is their difficult use at intermediate and high strain rates. In this study, a new experimental protocol to evaluate matrix crack density evolution at intermediate strain rates is proposed and applied to $\left[0 / 90_{3}\right]_{s}$ carbon/epoxy laminate. It is based on the use of passive infrared thermography to monitor the matrix cracking appearance. This methodology is used to first demonstrate that the crack appearance in the $90^{\circ}$ ply remains instantaneous from side to side with the increase of the strain rate. Finally, the rate insensitivity of the crack density as a function of the applied stress for the studied material in the studied range of strain rates $\left(8.3 \times 10^{-4}\right.$ up to $\left.6.69 \times 10^{-2} \mathrm{~s}^{-1}\right)$ is demonstrated.
\end{abstract}

\section{KEYWORDS}

composite materials, crack density, infrared thermography, strain rate dependency, transverse cracking

\section{1 | INTRODUCTION}

Organic matrix composite laminates are widely used in the transportation industry and particularly in the aeronautical industry. Despite this, sizing margins still need to be reduced in order to fully take advantage of the specific properties of these materials. To reduce sizing margins, confidence in the modelling tools must be increased, particularly regarding the rate effects that have been observed for these materials ${ }^{[1-4]}$. A significant number of advanced behaviour laws are available in the literature regarding quasi-static loadings ${ }^{[5-7]}$. The confidence in the advanced models has been given by the first two World-Wild Failure Exercises ${ }^{[8,9]}$. Regarding strain rate dependency, a recent increase in the available theories can be noticed ${ }^{[10-12]}$. The development and validation of strain-rate-dependent advanced models are sometimes limited, due to the lack of experimental data. For example, for carbon/epoxy materials, it is currently not possible to evaluate the capabilities of the advanced theories to predict the evolution of the matrix crack density with the applied loading at different strain rates, as will be done in the third WWFE for quasi-static loadings ${ }^{[13]}$. Innovative experimental procedures have to be proposed to be able to monitor matrix crack density evolution under dynamic loadings.

First, authors who have studied the matrix crack density evolution in a laminate have performed work on $\left[0_{m} / 90_{n}\right]_{s}$ GFRP laminates ${ }^{[14-16]}$. The crack density can be monitored optically thanks to the transparency of the laminate. To study CFRP materials, X-ray radiography has been used first ${ }^{[17,18]}$. Various other techniques have been used since these pioneer works: optical microscopy, ${ }^{[19-21]}$ full-field displacement measurements ${ }^{[22,23]}$ or high-resolution visible camera ${ }^{[24]}$. All of these different techniques cannot easily be used to monitor matrix cracking during a dynamic tensile test because of two major issues. First, interrupted dynamic tests are very complex; consequently, X-ray analysis and optical microscopy 
can only be performed as a post-mortem analysis. The last two techniques require sufficient resolution to be efficient, and with the increase in the strain rate, the camera resolution decreases even with high-speed cameras, leading to additional difficulties in the use of these techniques. Consequently, all of the studies available in the literature dealing with the time dependency of matrix cracking have been performed for low-speed tests or creep tests, typically lower than $10 \mathrm{~mm} \mathrm{~min}^{-1[25-27]}$.

Some authors have also used passive infrared thermography to monitor the damage appearance and growth into composite materials ${ }^{[28-30]}$. Battams and Dulieu-Barton ${ }^{[30]}$ performed DIC and infrared thermography on the same surface of a $[90,0]_{s}$ laminate and have shown that transverse cracks can be observed with the two measurement techniques at intermediate strain rate $\left(32 \mathrm{~s}^{-1}\right)$. The objective of this study is to fully use passive infrared measurement in order to evaluate the crack density evolution for CFRP material with respect to the strain rate in a CFRP laminate.

\section{2 | EXPERIMENTAL PROCEDURE}

\section{1 | Material}

The studied material is the HexPly M21/35\%/268/T700GC (Hexcel France) made of T700 carbon fibre and M21 epoxy resin. In this unidirectional laminate, the impact resistance has been improved by the inclusion of thermoplastic nodules in the epoxy resin. Laminate plates have been manufactured by hand lay-up and cured under a typical cure cycle in an autoclave. A symmetric and balanced stacking sequence has been chosen: $\left[0 / 90_{3}\right]_{s}$. Rectangular specimens were cut out of plates with a diamond saw. The specimens were $15 \mathrm{~mm}$ wide and $2.15 \mathrm{~mm}$ thick, with a 41-mm free length between the tabs. The tabs are made out of GFRP woven plies with a length of approximately $50 \mathrm{~mm}$.

\section{2 | Test set-up}

The experimental set-up is described in Figure 1. The experimental investigation is performed on a SCHENCK servo-hydraulic jack. Various constant upper holder speeds can be applied on the specimen from $5 \mathrm{~mm} \mathrm{~min}^{-1}$ up to $10 \mathrm{~m} \mathrm{~s}^{-1}$. In this study, three different upper holder speeds will be studied: 5, 50, and $500 \mathrm{~mm} \mathrm{~min}^{-1}$. For each speed, at least three specimens are tested in order to check discrepancies. The applied load is measured with a Kistler piezoelectric cell (Kistler 9071A). Pre-stressing is performed on the load cell in order to be able to measure the applied load between -200 and $+200 \mathrm{kN}$. To accurately evaluate the speed of the test, the upper holder displacement is measured with a Keyence laser transducer (KEYENCE LK-HD500 and LK-H052). The measurement of the specimen longitudinal strain is performed with two different measurement systems. A strain gauge, with a 2-mm grid (TML YFLA-2) is glued on the specimen surface. On the other side, the strain is measured with a Zimmer optical extensometer (Model 200XH) with two black-and-white transitions painted on the specimen surface as shown in Figure 2. The initial distance between



FIGURE 1 Experimental set-up 




FIGURE 2 Black-and-white transition painted on the specimen surface

the two transitions is approximately $32.5 \mathrm{~mm}$ and has been measured precisely for each specimen. The choice to use two different measurement techniques is based on the fact that the strain gauge measurement is more localised (2-mm grid) and consequently more sensitive to crack appearance under the grid. The strain measurement performed with the optical extensometer is less affected by crack appearance and consequently more macroscopic. Finally, the evolution of the edge surface temperature is monitored with a CEDIP LWIR Jade III infrared camera with a 50-mm LWIR objective. The camera sensor can capture $320 \times 240$ pixel images up to $250 \mathrm{~Hz}$ in full frame and up to $13 \mathrm{kHz}$ in line mode. In this study, a maximum frame rate of $1820 \mathrm{~Hz}$ will be used for tests performed at the highest speed. More information concerning the camera calibration and image analysis will be given in the next section, which is dedicated to infrared thermography measurement. Finally, to synchronise all measurement systems and record data, a 1-MHz data acquisition system is used (DEWETRON DEWE-2600).

\section{3 | Infrared thermography measurement}

In this study, an infrared camera is used to monitor the sample surface temperature. The principle of this measurement technique is that bodies at a temperature greater than $0 \mathrm{~K}$ emit infrared radiation, which is related to their temperature. If the emissivity of the body is known and if the camera has been calibrated, the thermal field on the specimen surface can be obtained using the infrared camera. During mechanical testing, the temperature of the specimen varies with the intensity of the applied load on the one hand and with the appearance of dissipative phenomena on the other hand ${ }^{[31]}$. As was mentioned, to obtain a quantitative measurement, the infrared camera has to be calibrated for each camera configuration (frequency, integration time, objective, etc.). In this study, the calibration is performed using an extended black body (HGH DCN1000H4) for temperatures close to ambient temperatures, according to the procedure proposed by Bodelot et al ${ }^{[32]}$. It consists in a pixel-by-pixel calibration leading to a calibration law for each pixel. The calibration procedure was performed in the same experimental environment. One hundred images of the black body surface have been obtained every $0.5^{\circ} \mathrm{C}$ between $20^{\circ} \mathrm{C}$ and $29^{\circ} \mathrm{C}$. The polynomial calibration law for each pixel is obtained by post-processing the images with the software Matlab ${ }^{\circledR}$. With regard to the emissivity of the specimen, since a carbon/epoxy material is considered, a high emissivity value can be used (typically higher than 0.9$)^{[33]}$. 
The trigger system of the JADE III camera is a computer-based system that involves a time uncertainty of $100 \mathrm{~ms}$. This uncertainty is unacceptable for the tests performed with an upper holder speed of $500 \mathrm{~mm} \mathrm{~min}{ }^{-1}$ with a duration of approximately $200 \mathrm{~ms}$. Given that $\left[0 / 90_{3}\right]_{s}$ carbon/epoxy specimens are used, the failure is brittle and a significant amount of energy is released during this brittle failure. Consequently, the failure of such a specimen is clearly visible in infrared images. The time synchronisation of the infrared measurement with the other measured data is based on the final failure of the coupon.

Finally, the thermal field analysis can classically be performed in two ways ${ }^{[34]}$. Usually, the analysis is performed by comparing the thermal field at a time step $t$ with the initial thermal field at the time step $t_{0}$ as proposed by Meola and Carlomagno ${ }^{[35]}$. In that case, the thermal change field $\Delta T$ is obtained. This field includes the temperature variation due to thermoelasticity and due to dissipative phenomena. In the sequel, the time step $t_{0}$ corresponds to an image captured a few milliseconds before the load application. The time step $t$ corresponds to the current time step.

\section{3 | RESULTS AND DISCUSSIONS}

Transverse cracking in $\left[0_{m} / 90_{n}\right]_{s}$ laminates is known to be instantaneous in the $90^{\circ}$ ply from side to side, if the thickness of the ply is sufficiently high ${ }^{[36]}$. For the T700/M21 composite material, Huchette performed tests on laminates, also with six plies oriented at $90^{\circ}$, and transverse cracking can be considered instantaneous from side to side ${ }^{[37]}$. In this work, a preliminary study with a specific set-up is performed in order to evaluate whether the transverse cracking can still be considered as instantaneous with the increase in the strain rate. After this preliminary investigation, the results obtained at different strain rates with the experimental set-up described previously are detailed.

\section{1 | Preliminary investigation}

In this work, a preliminary study has been proposed to ensure that the transverse cracking remains instantaneous from side to side with the strain rate increase. If that is the case, only the edge surface of the specimen can be monitored. Consequently, a lower spatial resolution for the infrared measurement can be used, allowing the use of a higher frame rate. For that specific study, another experimental set-up has been used in order to be able to image an edge and a face of the specimen at the same time. The tests have been performed with the servo-hydraulic jack previously presented. The infrared camera is positioned at an angle of $69^{\circ}$ with respect to the normal of the specimen face in order to visualise the edge and the face on the same image as shown in Figure 3. For this specific set-up, in order to avoid infrared measurement perturbation, the black-and-white transition used to measure the strain with the optical extensometer has not been applied on the specimen. The strain is only measured with a strain gauge glued onto the opposite face. Due to the decrease in the emissivity with the angle view, the thermal field obtained with the infrared camera is no longer quantitative. Henceforth,


FIGURE 3 Description of preliminary investigation set-up, on the left-hand side, and description of the viewed frame, on the right-hand side 


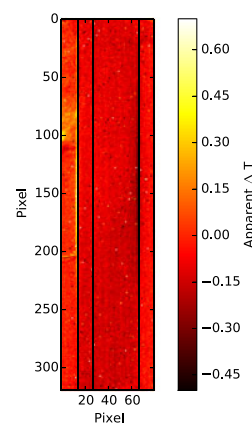

(a) $20 \% \sigma_{\max }$



(b) $40 \% \sigma_{\max }$

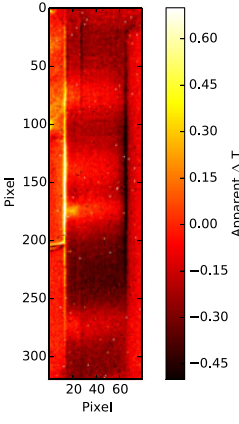

(c) $60 \% \sigma_{\max }$

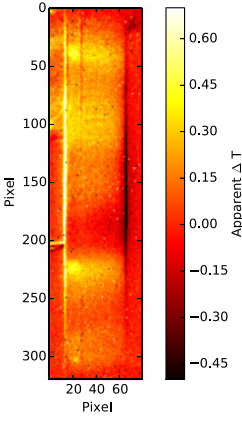

(d) $80 \% \sigma_{\max }$

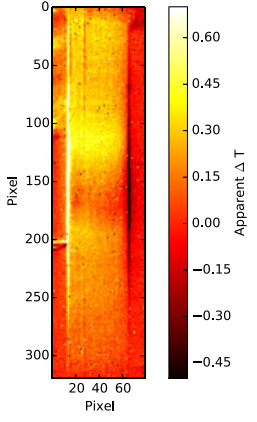

(e) $95 \% \sigma_{\max }$

FIGURE 4 Evolution of the variation of the apparent temperature with respect to the load applied on the specimen

the measured temperature is consequently called apparent temperature. However, the apparent temperature offers access to the increase in temperature due to matrix crack appearance, which is sufficient in this case.

First, the tensile test has been performed for the lower upper holder speed $\left(5 \mathrm{~mm} \mathrm{~min}^{-1}\right)$ with an acquiring frequency of $381 \mathrm{~Hz}$ and an integration time of $300 \mu \mathrm{s}$. The evolution of the apparent temperature variation with respect to the applied load is plotted in Figure 4. In this figure, the three observable edges of the specimen have been plotted on the left-hand-side picture: The abscissa of the first one is $x=15$, that of the second one is $x=28$, and that of the third one is $x=67$. As expected, the specimen apparent temperature decreases at the beginning of the test due to thermoelasticity, as can be noticed in the first three images in Figure 4. In Figure 4c, some areas of the specimen have a higher temperature than the rest of the coupon. These four hotter areas indicate that at least four damage events have occurred between $40 \%$ and $60 \%$ of the maximum load. In the last two images of Figure 4, other damage events can be observed, and the variation of the apparent temperature of the specimen is globally positive, particularly for the picture taken at $95 \%$ of the maximum load.

The first transverse crack appearance can be studied in more detail. In Figure 5, the apparent temperature variation is plotted at different times after the first transverse crack appearance. Images are plotted every five captured images that lead to a time interval of approximately $13 \mathrm{~ms}$. The images clearly show that the crack can first be detected on the specimen edge. After few tens of milliseconds, the temperature increase is also visible on the specimen face. The amount of time required to detect the temperature increase on the face of the specimen is related to the diffusion of the temperature through the thickness of the $0^{\circ}$ ply. The results plotted in Figure 5 do not show a high variation in the apparent temperature between the left-hand side and the right-hand side of the specimen face, which can reveal a delay in the propagation of the crack from side to side. To fully assess this result, three small areas on the specimen face have been used to compute the mean variation of the temperature in these areas after the first crack appearance. The three different areas are plotted in the left-hand-side cartoon of Figure 5, in blue for the first area close to the observable edge $(x \in[29 ; 36]$ and $y \in[139 ; 141])$, in red for the area in the middle of the sample ( $x \in[43 ; 50]$ and $y \in[139 ; 141])$, and in green for the area close to the opposite edge ( $x \in[57 ; 64]$ and $y \in[139 ; 141])$. Given that the angle of view between the three areas is not the same, the temperature variation has been divided by the maximum value in each area in order to reduce the influence of the emissivity variation on the result. The results plotted in Figure 6 exhibit no major differences between the three areas. The same analysis can be performed for all cracks leading to the same conclusion. Consequently, these results lead to the conclusion that the crack propagation from side to side can be considered instantaneous at this testing speed.

Finally, this preliminary study has revealed some crack events that are not fully developed in the thickness of the ply. An example of one of these partial events is shown in Figure 7. As previously shown, the event is first visible on the specimen edge. The temperature increase appears later on the specimen surface. For some of these partial cracks, the crack path in the thickness is completed for a higher stress level. Some of these partial cracks remain incomplete up until the specimen failure. Henceforth, only complete cracks in the thickness will be taken into account. For some partial cracks, the full propagation in the thickness can be obtained later during the test at a higher load level. In this case, the contribution of this crack to the crack density will be added when the crack is fully developed.

To study the influence of the testing speed on the immediacy of the transverse crack propagation, tensile tests have been performed for two different upper holder speeds of 50 and $500 \mathrm{~mm} \mathrm{~min}^{-1}$. The infrared camera configuration has been modified to use a higher acquiring frequency. The frequency is $700 \mathrm{~Hz}$, and the integration time is $205 \mu \mathrm{s}$. As previously, the first crack appearance is plotted in Figure 8. The same time step of $13 \mathrm{~ms}$ is used for the different images in this figure 


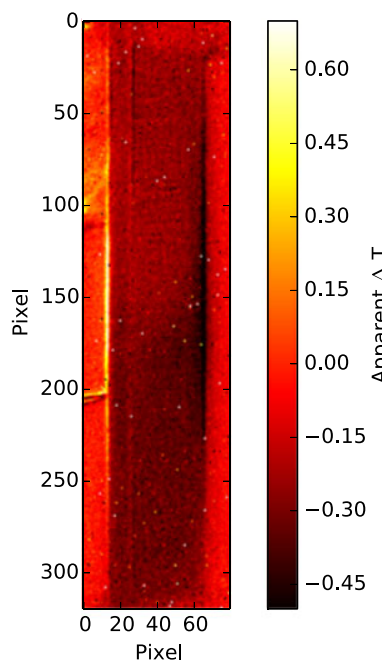

(a) $t=t_{\text {first } \mathrm{crack}}-13 \mathrm{~ms}$

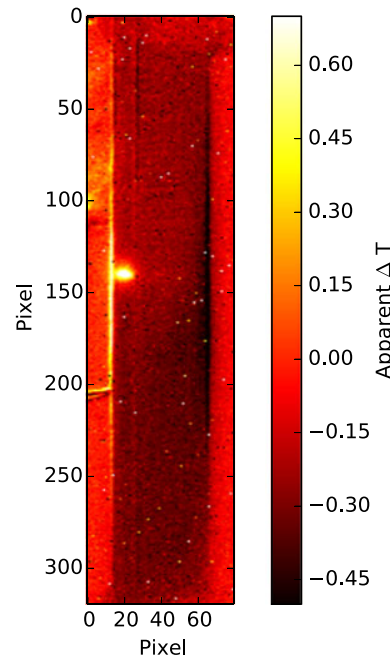

(d) $t=t_{\text {first crack }}+26 \mathrm{~ms}$

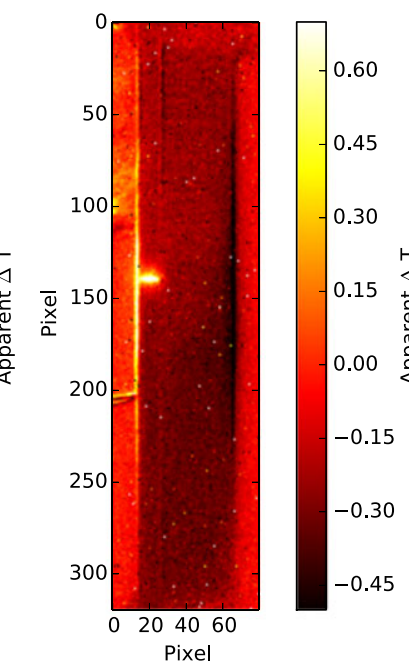

(b) $t=t_{\text {first crack }}$

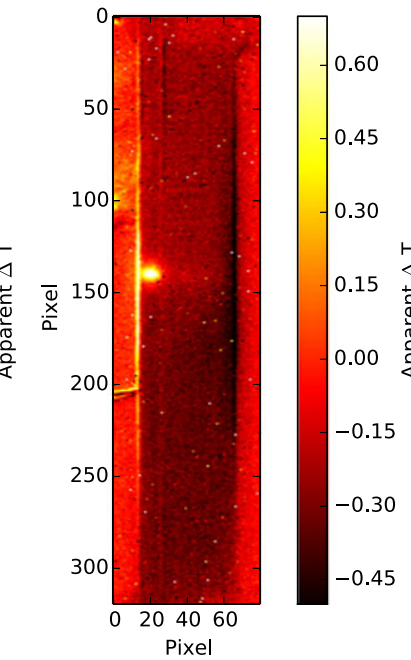

(e) $t=t_{\text {first }}$ crack $+39 m s$

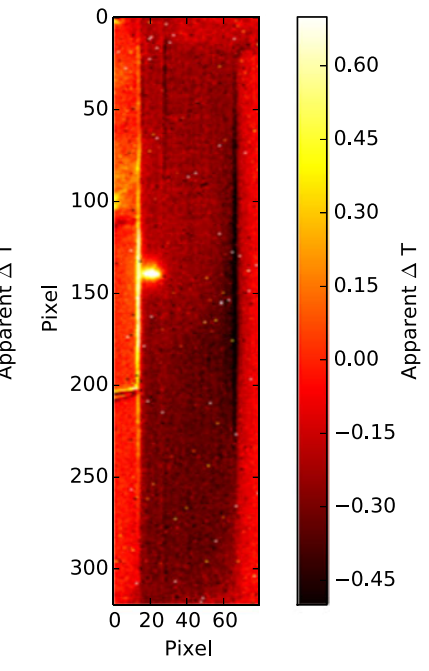

(c) $t=t_{\text {first crack }}+13 m s$

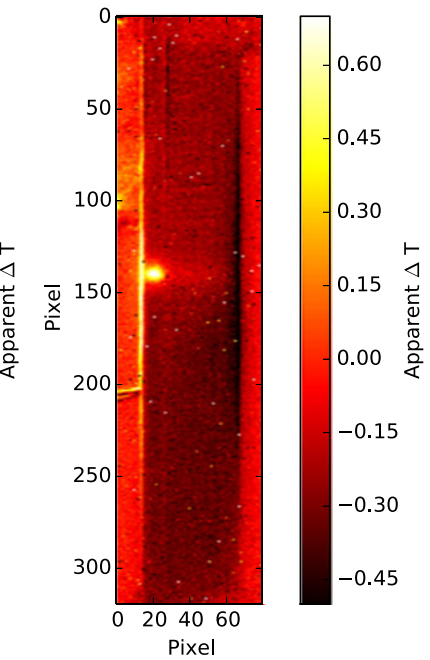

(f) $t=t_{\text {first crack }}+52 m s$

FIGURE 5 Evolution of the apparent temperature variation after the first transverse crack appearance, for a test performed at $5 \mathrm{~mm} \mathrm{~min}^{-1}$


FIGURE 6 Comparison of the temperature variation in three different areas on the specimen face (as shown on the left-hand side cartoon), for times close to those of the first crack appearance, for a test performed at $5 \mathrm{~mm} \mathrm{~min}^{-1}$ 


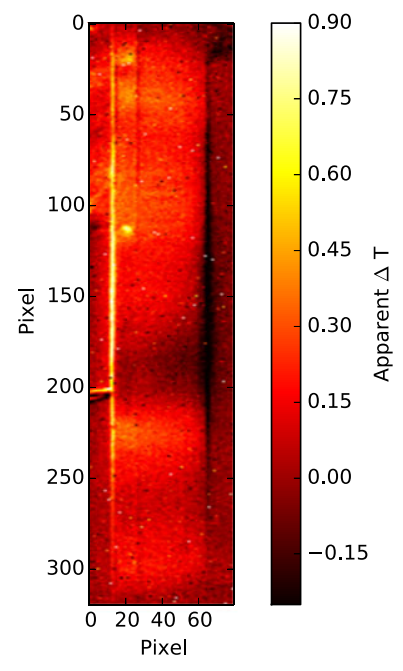

(a) $t=t_{\text {crack }}$



(b) $t=t_{\text {crack }}+13 m s$

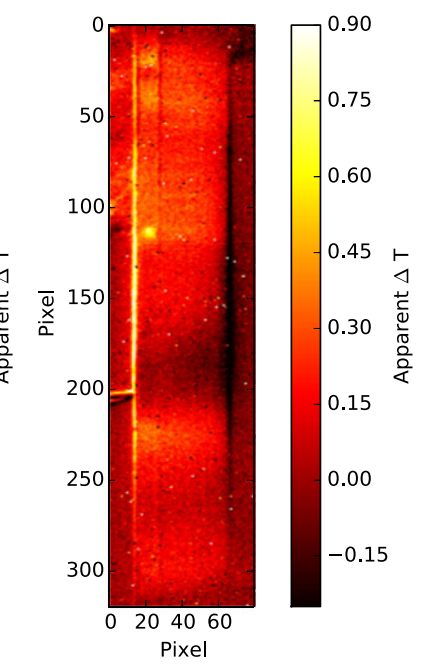

(c) $t=t_{\text {crack }}+26 m s$

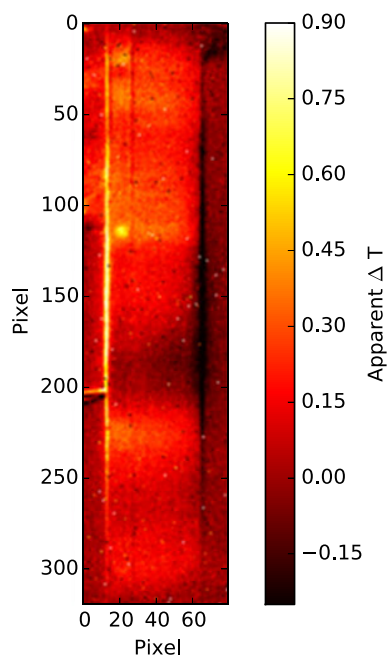

(d) $t=t_{\text {crack }}+39 \mathrm{~ms}$

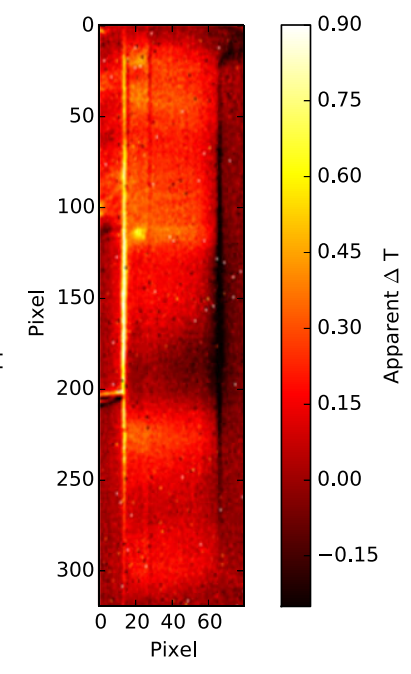

(e) $t=t_{\text {crack }}+52 m s$

FIGURE 7 Evolution of the apparent temperature variation after a crack appearance (later than the first crack), which is not fully developed in the thickness for $\sigma=81 \% \sigma_{\max }$

(one image is plotted every nine images taken). The same phenomenology is observed with a crack firstly visible on the edge. After diffusion, the crack is also visible on the specimen surface. For this configuration, another crack appears in this time interval at the top of the last two pictures in Figure 8. Regarding the crack localisation in the sample, all the tests performed in this study have shown different spatial localisation for the first crack. To assess the immediacy, the procedure presented previously is used. The mean value is plotted in Figure 9 in blue for the first area close to the observable edge $(x \in[22 ; 28]$ and $y \in[266 ; 268])$, in red for the area in the middle of the sample $(x \in[43 ; 49]$ and $y \in[266 ; 268])$, and in green for the first area close to the opposite edge $(x \in[64 ; 70]$ and $y \in[266 ; 268])$. As previously observed for the test at $5 \mathrm{~mm} \mathrm{~min} \mathrm{~m}^{-1}$, no major differences are observed between the three areas.

The same infrared camera configuration has been used for the tensile test performed at $500 \mathrm{~mm} \mathrm{~min}^{-1}$, and the same protocol has been used to analyse the immediacy of the transverse crack appearance. The mean value is plotted in Figure 10 in blue for the first area close to the observable edge $(x \in[22 ; 28]$ and $y \in[165 ; 167])$, in red for the area in the middle of the sample $(x \in[43 ; 49]$ and $y \in[165 ; 167])$, and in green for the first area close to the opposite edge ( $x \in[64 ; 70]$ and $y \in[165 ; 167])$. No time difference is observed between the three areas. The same results are obtained for the different cracks that appear during the tests. The results presented in Figure 10 are noisier than are the results for lower loading rates. Various explanations can be proposed. First, at this displacement rate, more than 20 other cracks 


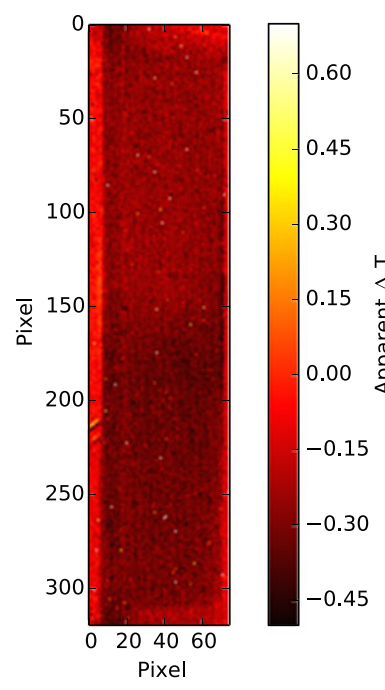

(a) $t=t_{\text {first crack }}-13 \mathrm{~ms}$

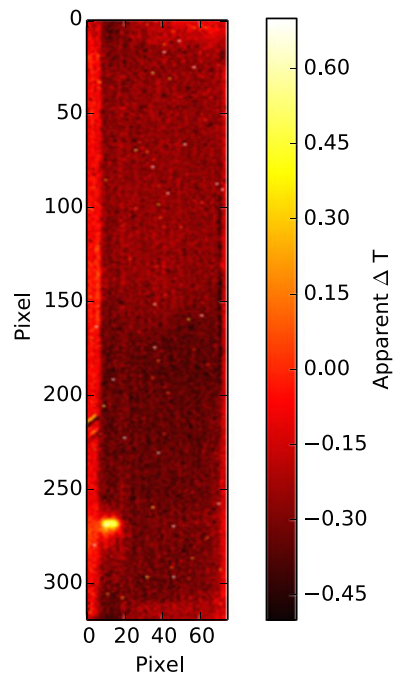

(d) $t=t_{\text {first crack }}+26 m s$

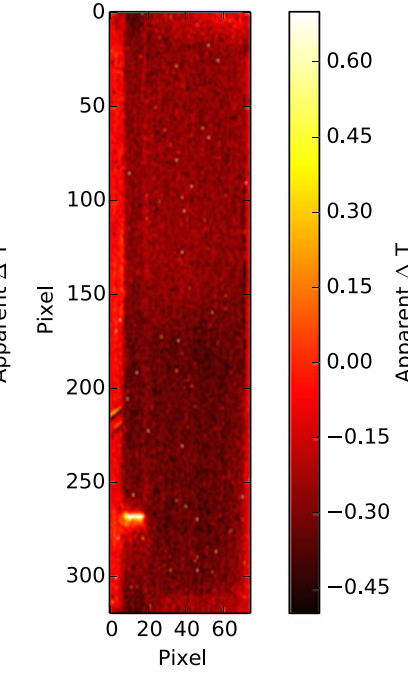

(b) $t=t_{\text {first } \text { crack }}$

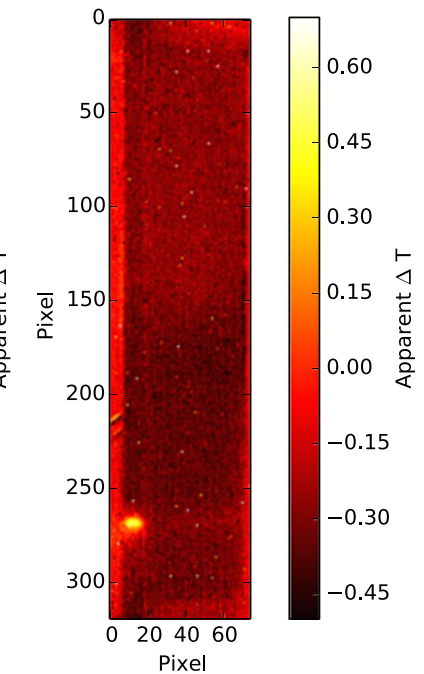

(e) $t=t_{\text {first crack }}+39 m s$

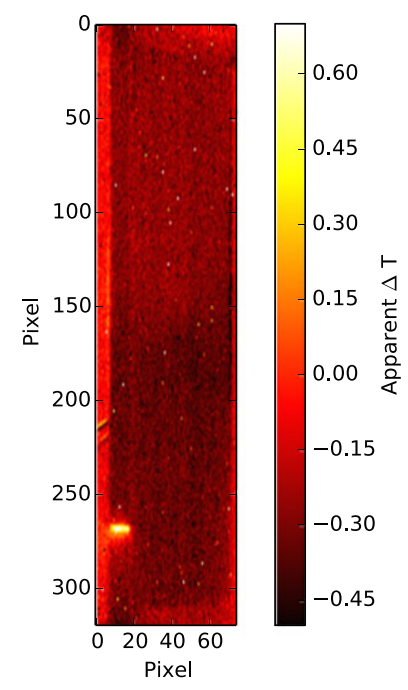

(c) $t=t_{\text {first crack }}+13 \mathrm{~ms}$

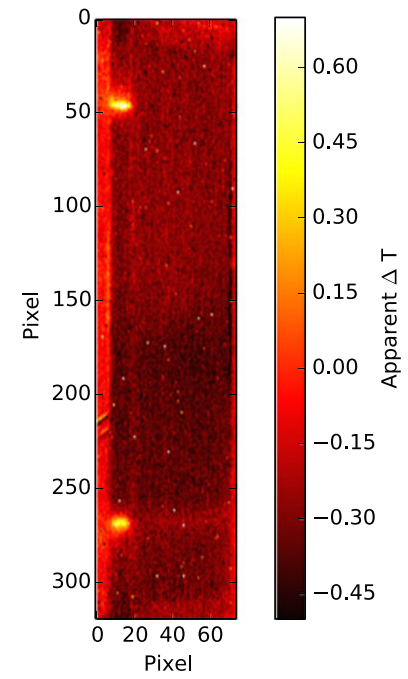

(f) $t=t_{\text {first crack }}+52 m s$

FIGURE 8 Evolution of the apparent temperature variation after the first transverse crack appearance, for a test performed at $50 \mathrm{~mm}^{\mathrm{min}}{ }^{-1}$

appear during the $100 \mathrm{~ms}$ (only two for the $50 \mathrm{~mm} \mathrm{~min}^{-1}$ test), which can perturb the measurements. As different pixels of the sensor are used, the noise can be higher, which can perturb the analysis, all the more as small temperature variations are measured. Finally, environmental perturbation could have come into play due to fact that the different tests were not performed at the same moment of the day. These results lead to the conclusion that the transverse crack appearance can still be considered instantaneous from side to side with the loading rate increase.

\section{2 | Application on a tensile test performed at $5 \mathrm{~mm} \mathrm{~min}^{-1}$}

Three specimens have been tested with an upper holder setpoint speed of $5 \mathrm{~mm} \mathrm{~min}^{-1}$. The mean obtained speed for the three tests is $4.5 \pm 0.1 \mathrm{~mm} \mathrm{~min}^{-1}$, leading to an average strain rate of $8.3 \times 10^{-4} \mathrm{~s}^{-1}$. An example of the stress and strain measurements obtained is plotted in Figure 11. At the beginning of the test, the strain measured with the strain gauge is superimposed on the strain measured with the optical extensometer. With the increase of the applied stress, the two curves start to diverge for a stress of approximately $300 \mathrm{MPa}$. After the curve separation, a sharp increase in the strain measured by the strain gauge can be observed. In Figure 12, the recorded signals are focused on the times close to the sharp increase observed in the strain gauge measurement. During this test, all of the signals are recorded with a frequency of $100 \mathrm{kHz}$. In 

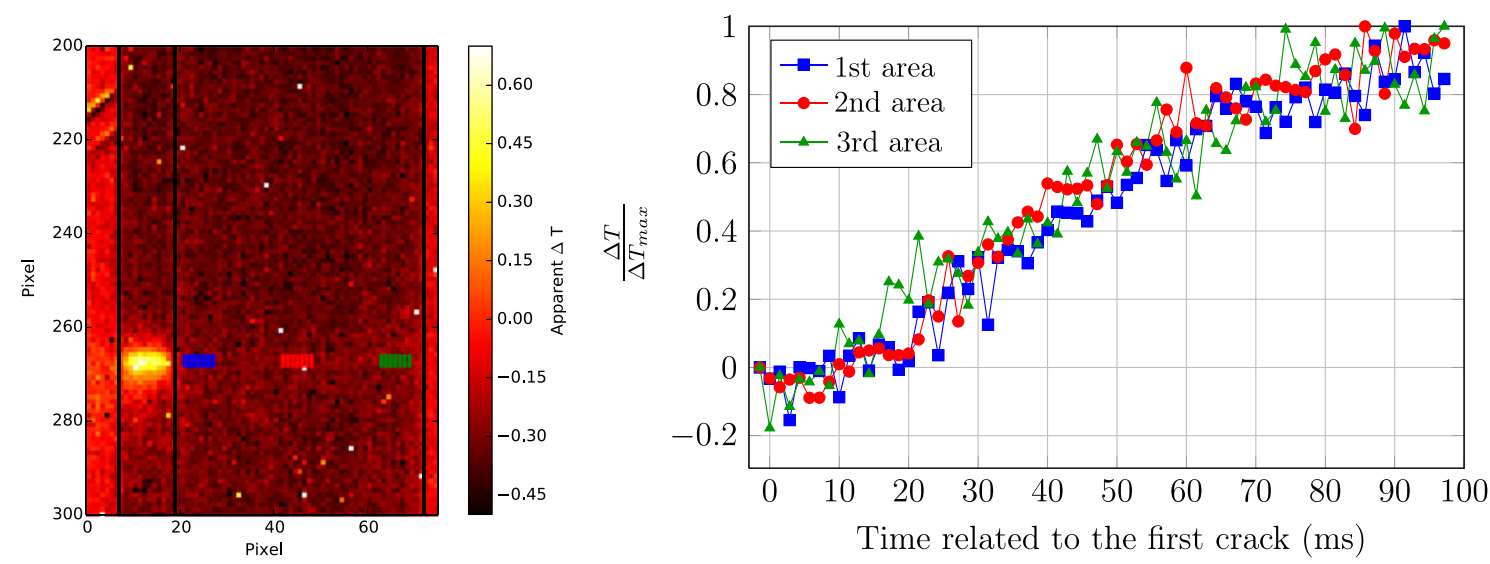

FIGURE 9 Comparison of the temperature variation in three different areas on the specimen face (as shown on the left-hand-side cartoon), for times close to those of the first crack appearance, for a test performed at $50 \mathrm{~mm} \mathrm{~min}^{-1}$
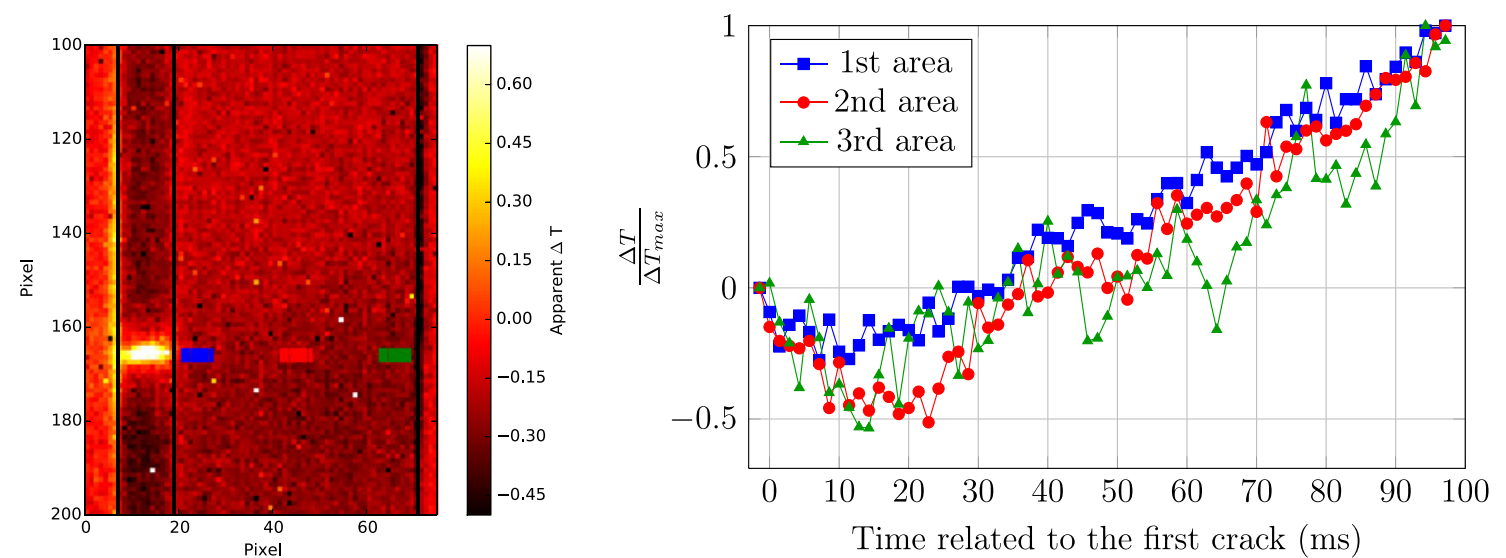

FIGURE 10 Comparison of the temperature variation in three different areas on the specimen face (as shown on the left-hand-side cartoon), for times close to those of the first crack appearance, for a test performed at $500 \mathrm{~mm} \mathrm{~min}^{-1}$

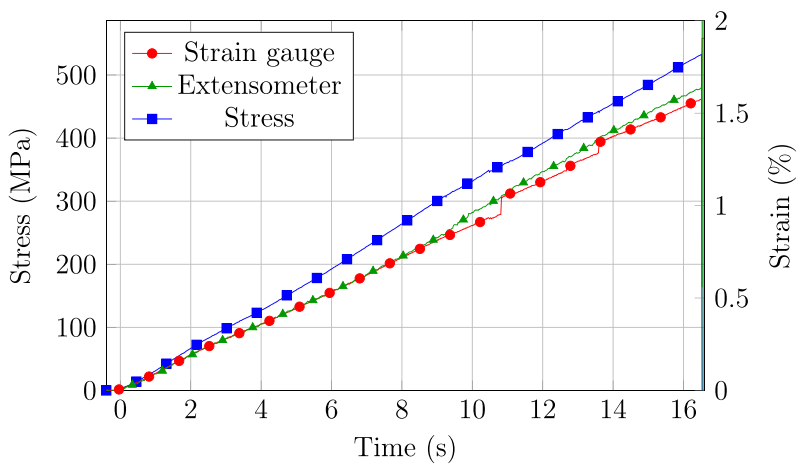

FIGURE 11 Evolution of the measured stress and strain during a test performed at $5 \mathrm{~mm} \mathrm{~min}^{-1}$

Figure 12, the event observed in the strain measurement is correlated with an event observed in the stress signal recorded at $100 \mathrm{kHz}$. In order to illustrate the influence of the acquiring frequency, the stress is also plotted for a signal recorded at $10 \mathrm{kHz}$ and a signal recorded at $1 \mathrm{kHz}$. For the signal recorded at $1 \mathrm{kHz}$, the event observed on stress signal starts to become difficult to detect. For lower acquiring frequencies, the event is missed. To characterise that event, the infrared measurement can be analysed. For this loading speed, an integration time of $300 \mu \mathrm{s}$ and an acquiring frequency of $400 \mathrm{~Hz}$ have been used. With this configuration, a $2.5-\mathrm{ms} \mathrm{time} \mathrm{uncertainty} \mathrm{is} \mathrm{obtained} \mathrm{for} \mathrm{the} \mathrm{crack} \mathrm{appearance} \mathrm{detection,} \mathrm{leading}$ to a maximum stress uncertainty lower than 0.1 MPa. In Figure 13, two infrared images captured in the time interval 


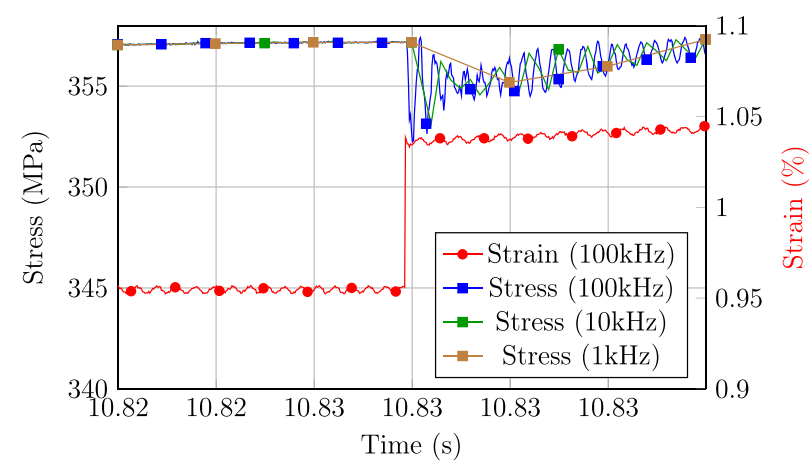

FIGURE 12 Close-up of the evolution of the measured stress and strain close to a sharp increase in the strain measured with the strain gauge during a test performed at $5 \mathrm{~mm} \mathrm{~min}^{-1}$

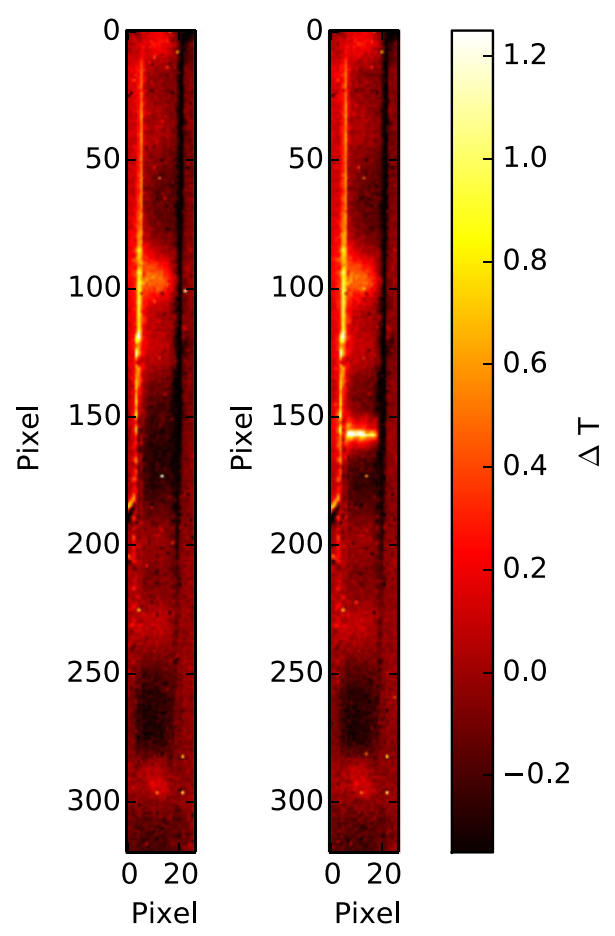

$\begin{array}{ll}\text { (a) } t_{I R}=10.823 \mathrm{~s} & \text { (b) } t_{I R}=10.826 \mathrm{~s}\end{array}$

FIGURE 13 Evolution of the surface temperature variation for two different times close to the sharp increase observed in Figure 12

of Figure 12 are plotted. For the two images, the wire of the strain gauge can be observed on the left-hand side for the pixels between 180 and 190. For $t_{\mathrm{IR}}=10.826 \mathrm{~s}$, a warm zone appears in the middle of the specimen, just below the strain gauge. Consequently, the sharp increase observed on the strain gauge is clearly due to the crack appearance below the measurement grid. The crack appearance is also correlated with a disruption of the load signal as it can be seen in Figure 12. Consequently, the time uncertainty due to the acquiring frequency of the infrared camera can be avoided by using the crack appearance time obtained with the load signal. Despite this result, a cross-analysis of the load signal and infrared images is required to accurately evaluate the crack density evolution, because the load signal disruption is quite similar for a single crack or simultaneous cracks. By using this cross-analysis of infrared thermography images and load signal disruption, the crack density evolution for the different specimens is plotted in Figure 14. First of all, Figure 14 shows a good repeatability of the evolution law. No saturation of the crack density is observed probably due to the significant width of the $90^{\circ}$ plies. A mean value of $294 \mathrm{MPa} \pm 8 \%$ is obtained for the stress applied to the laminate at the first crack appearance. The mean value of the maximum stress applied to the coupon is $515 \mathrm{MPa} \pm 5 \%$. For the first test, a lower crack density is reached before the failure of the coupon, but the specimen is also the one that fails at the lower applied stress (493 MPa). The crack density obtained in this study can be compared with that obtained by Huchette ${ }^{[37]}$. 


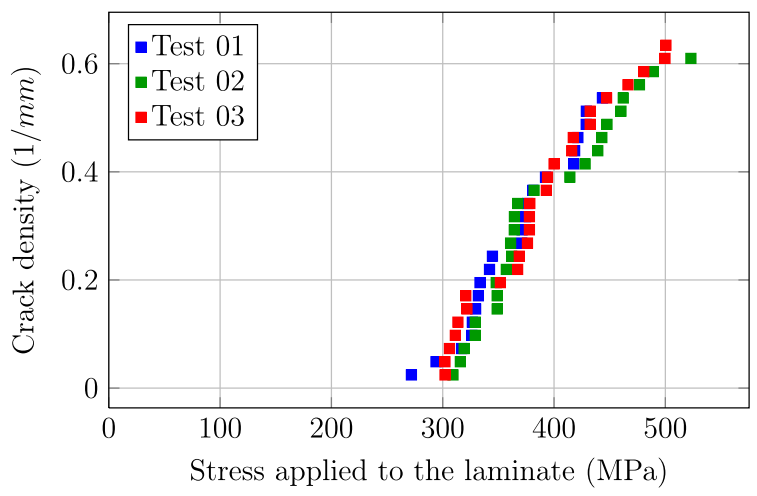

FIGURE 14 Evolution of the crack density measured with respect to the stress applied, for three different specimens tested at 5 mm min ${ }^{-1}$

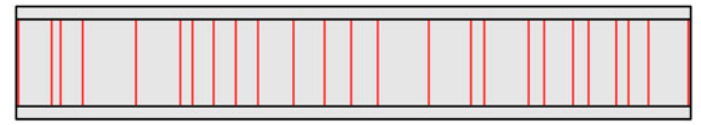

FIGURE 15 Schematic representation of the crack location for a specimen tested at $5 \mathrm{~mm} \mathrm{~min}^{-1}$

Huchette performed quasi-static tests on the same composite material with a $\left[0_{2} / 90_{3}\right]_{s}$ stacking sequence, and the crack density was evaluated through optical microscopy images. A maximum crack density between 0.3 and 0.6 was obtained for the different samples tested. A crack density of the same order of magnitude is obtained in this study for the same thickness of the $90^{\circ}$ plies. Figure 14 shows the advantage of the proposed methodology. For each crack generated, the exact applied load is known, leading to increased accuracy in the evolution law of the crack density with respect to the applied load. Finally, the location of each crack for the test labelled Test 02 is plotted in Figure 15. The cracks are spread throughout the free length of the specimen. No typical cracking pattern appears over the entire free length, which also confirms that the crack saturation is not reached during these tests.

\section{3 | Application on a tensile test performed at $50 \mathrm{~mm} \mathrm{~min}^{-1}$}

Three specimens have been tested with an upper holder setpoint speed of $50 \mathrm{~mm} \mathrm{~min}^{-1}$. The mean speed obtained for the three tests is $35.9 \pm 0.7 \mathrm{~mm} \mathrm{~min}^{-1}$, leading to an average strain rate of $6.46 \times 10^{-3} \mathrm{~s}^{-1}$. For this loading speed, an integration time of $300 \mu \mathrm{s}$ and an acquiring frequency of $1000 \mathrm{~Hz}$ have been used. With this configuration, a 1-ms time uncertainty is obtained for the crack appearance detection, leading to a maximum stress uncertainty lower than $0.3 \mathrm{MPa}$. As previously, the cross-analysis of the infrared images and load signal has been performed in order to evaluate the crack density evolution during the test. The results are plotted in Figure 16. At this higher loading rate, the repeatability of the test results remains very good. A mean value of $274 \mathrm{MPa} \pm 10 \%$ is obtained for the applied stress on the laminate at the first crack appearance. This value is slightly lower than the measured value for the $5 \mathrm{~mm} \mathrm{~min}^{-1}$ tests, but no conclusion concerning a possible rate effect could be established, due to the discrepancy observed. With regard to the maximum stress applied to the laminate, a mean value of $514 \mathrm{MPa} \pm 8 \%$ is obtained, which is similar to the lower strain rate. Finally, a maximum crack density between 0.44 and 0.6 is obtained for this loading rate, which is also in good agreement with the previously obtained results. Concerning the location of the crack in the specimen, a schematic representation is shown in Figure 17 for the test labelled Test 01. The same conclusions arise of this figure: The cracks are spread throughout the free length, without a typical pattern.

\section{4 | Application on a tensile test performed at $500 \mathrm{~mm} \mathrm{~min}^{-1}$}

As previously, three specimens were tested with an upper holder setpoint speed of $500 \mathrm{~mm} \mathrm{~min} \mathrm{~m}^{-1}$. The mean speed obtained for the three tests is $394 \pm 16 \mathrm{~mm} \mathrm{~min}^{-1}$, leading to an average strain rate of $6.69 \times 10^{-2} \mathrm{~s}^{-1}$. For this loading speed, an integration time of $150 \mu \mathrm{s}$ and an acquiring frequency of $1820 \mathrm{~Hz}$ were used. With this configuration, a $0.55-\mathrm{ms}$ time uncertainty was obtained for the crack appearance detection, leading to a maximum stress uncertainty lower than 3.5 MPa. Given that a cross-analysis between the infrared images and the load signal is performed, in most cases, this 


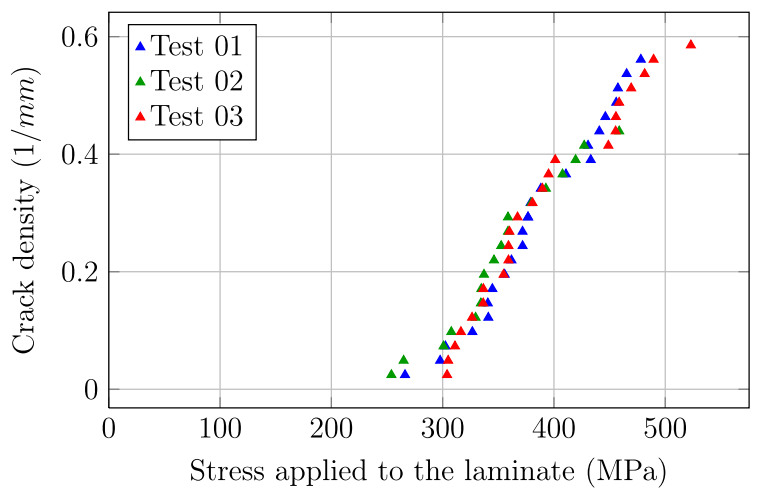

FIGURE 16 Evolution of the crack density measured with respect to the stress applied, for three different specimens tested at $50 \mathrm{~mm}^{\mathrm{min}}{ }^{-1}$

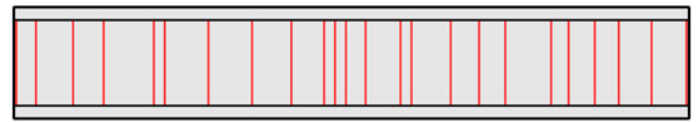

FIGURE 17 Schematic representation of the crack location for a specimen tested at $50 \mathrm{~mm} \mathrm{~min}^{-1}$



FIGURE 18 Evolution of the crack density measured with respect to the stress applied, for three different specimens tested at $500 \mathrm{~mm}^{\mathrm{min}}{ }^{-1}$

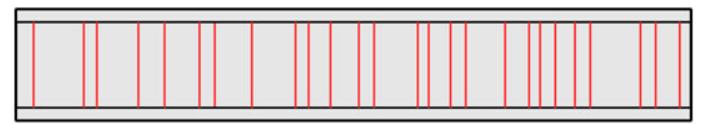

FIGURE 19 Schematic representation of the crack location for a specimen tested at $500 \mathrm{~mm} \mathrm{~min}^{-1}$

uncertainty can be reduced with the detection of a load signal disruption due to crack appearance. The evolution of the crack density with respect to the stress applied to the laminate is plotted in Figure 18. As for lower loading rates, a small discrepancy in the crack density evolution is observed between the different samples. A mean value of $301 \mathrm{MPa} \pm 5 \%$ is obtained for the stress applied to the laminate at the first crack appearance. The mean value is slightly higher for this loading rate, but, as previously, no conclusion can be reached due to the discrepancy. For this loading speed, a mean value of $510 \mathrm{MPa} \pm 5 \%$ is measured for the maximum stress applied to the laminate. This value is very close to the previously measured value for lower loading rates. A maximum value between 0.5 and 0.7 is obtained for the crack density before the failure of the specimen for this configuration. This value is also in good agreement with the previously obtained results. Finally, the location of each crack for the test labelled Test 03 is plotted in Figure 19. As previously observed for lower loading rates, cracks are spread throughout the free length, without a typical pattern. 


\section{5 | Rate sensitivity analysis}

Based on the previously presented results, the loading rate sensitivity will be analysed in the following paragraph. First of all, the different stress-strain responses with respect to the loading rate are plotted in Figure 20. For the strain measurement, the optical extensometer measurement, which is more global, is used. In this figure, the stress-strain response is superimposed whatever the strain rate is. As was previously mentioned, the maximum stress value applied to the laminate can be considered as rate-insensitive. The stress at which the first crack appeared can also be considered as rate-insensitive. Finally, in Figure 21, the crack density evolution with respect to the applied load is plotted for the different strain rates. This figure also shows the rate insensitivity of the crack density evolution with the applied load for this material configuration, in this range of loading rates.

These results can be compared with those of the literature. First of all, Tong et al ${ }^{[38]}$. performed tests on a $[0 / 90]_{s}$ GFRP laminate for loading rates between 0.05 and $20 \mathrm{~mm} \mathrm{~min}^{-1}$. They showed that the crack density as a function of the applied stress is rate-insensitive. Raghavan and Meshii ${ }^{[26]}$ performed tests on $\left[0 / 90_{4}\right]_{s}$ CFRP laminate for constant strain rates between $10^{-5}$ and $10^{-3} \mathrm{~s}^{-1}$. They found a rate sensitivity of the crack density as a function of the applied stress with optical microscopy. Finally, Nguyen and Gamby ${ }^{[27]}$ studied a $\left[0_{3} / 90_{3}\right]_{s}$ CFRP laminate at $120^{\circ} \mathrm{C}$, for loading rates between 0.01 and $10 \mathrm{~mm} \mathrm{~min}^{-1}$. They also found a rate sensitivity of the crack density as a function of the applied stress with optical microscopy at this temperature. The results obtained in this study are in agreement with the results obtained by Tong et al. ${ }^{[38]}$ on another material system. Their results cannot directly compare with those obtained by Nguyen and Gamby, ${ }^{[27]}$ because of the change in the environmental temperature, which is known to highly affect the viscosity of the thermoset resin ${ }^{[39]}$. Finally, the tests performed by Raghavan and Meshii ${ }^{[26]}$ were performed at lower strain rate, which could lead to the conclusion that the rate sensitivity is stronger for low strain rates than for intermediate strain rates.

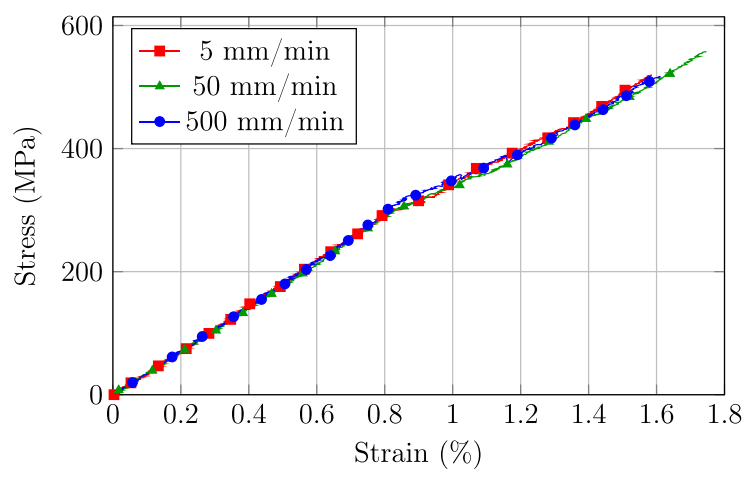

FIGURE 20 Stress-strain curves of the $\left[0 / 90_{3}\right]_{s}$ laminate at different loading rates

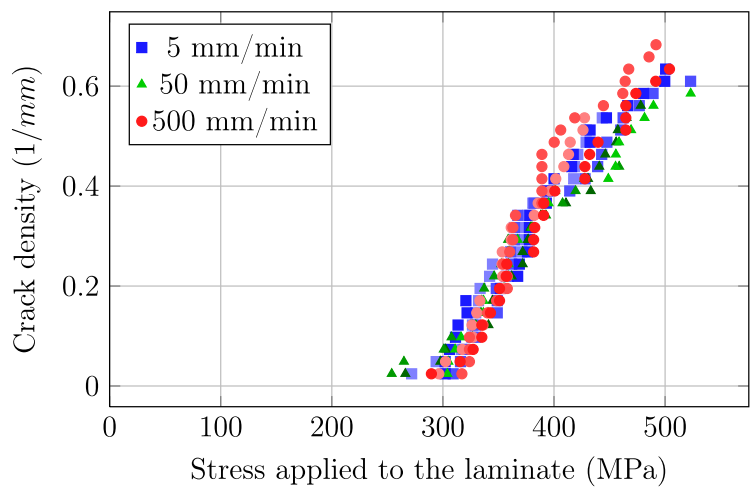

FIGURE 21 Evolution of the measured crack density with respect to the stress applied, for different specimens tested at different loading rates 


\section{CONCLUSIONS}

In this study, a new experimental protocol based on infrared thermography has been proposed to evaluate the crack density evolution in cross-ply laminates at intermediate strain rates and high strain rates. It consists in the measurement of $90^{\circ}$ ply crack appearance with an infrared camera at different loading rates. Due to the acquiring frequency of the current infrared sensor, the capabilities of this methodology have been demonstrated only for strain rates considered between low and intermediate range $\left(8.3 \times 10^{-4}\right.$ up to $\left.6.69 \times 10^{-2} \mathrm{~s}^{-1}\right)$. The study was performed on $\left[0 / 90_{3}\right]_{s}$ carbon/epoxy specimens. Preliminary tests were performed to demonstrate that the crack propagation from side to side remains instantaneous with the loading rate increase. Afterwards, the methodology proposed was applied for different loading rates. No rate sensitivity of the crack density as a function of the applied stress was observed for the studied material with this specific stacking sequence within the loading rate interval.

\section{ORCID}

J. Berthe (iD) http://orcid.org/0000-0003-1383-5923

\section{REFERENCES}

[1] I. Daniel, R. LaBedz, T. Liber, Exp. Mech. 1981, 21(2), 71.

[2] A. Gilat, R. K. Goldberg, G. D. Roberts, Compos. Sci. Technol. 2002, 62(10), 1469.

[3] T. Gomez-del Rio, E. Barbero, R. Zaera, C. Navarro, Compos. Sci. Technol. 2005, 65(1), 61.

[4] H. Koerber, J. Xavier, P. Camanho, Mech. Mater. 2010, 42(11), 1004.

[5] S. Pinho, L. Iannucci, P. Robinson, Composites Part A: Appl. Sci. Manuf. 2006, 37(1), 63.

[6] F. Laurin, N. Carrere, J-F Maire, Composites Part A: Appl. Sci. Manuf. 2007, 38(1), 198.

[7] E. Abisset, F. Daghia, P. Ladevèze, Composites Part A: Appl. Sci. Manuf. 2011, 42(10), 1515.

[8] P. Soden, A. Kaddour, M. Hinton, Compos. Sci. Technol. 2004, 64(3), 589.

[9] M. Hinton, A. Kaddour, J. Compos. Mater. 2012, 46(19-20), 2283.

[10] I. Daniel, B. Werner, J. Fenner, Compos. Sci. Technol. 2011, 71(3), 357.

[11] L. Raimondo, L. Iannucci, P. Robinson, P. Curtis, Compos. Sci. Technol. 2012, 72(7), 819.

[12] Y. Tao, H. Chen, K. Yao, H. Lei, Y. Pei, D. Fang, Int. J. Solids Struct. 2016, 113-114, 37.

[13] A. Kaddour, M. Hinton, P. Smith, S. Li, J. Compos. Mater. 2013, 47(20-21), 2749.

[14] K. Garrett, J. Bailey, J. Mater. Sci. 1977, 12(1), 157.

[15] A. Parvizi, K. Garrett, J. Bailey, J. Mater. Sci. 1978, 13(1), 195.

[16] J. Bailey, A. Parvizi, J. Mater. Sci. 1981, 16(3), 649.

[17] F. Crossman, W. Warren, A. Wang, G. Jr Law, J. Compos. Mater. 1980, 14(1), 88.

[18] S. Groves, C. Harris, A. Highsmith, D. Allen, R. Norvell, Exp. Mech. 1987, 27(1), 73.

[19] J. Varna, R. Joffe, N. Akshantala, R. Talreja, Compos. Sci. Technol. 1999, 59(14), 2139.

[20] C. Huchette, D. Lévêque, N. Carrère, in IUTAM Symposium on Multiscale Modelling of Damage and Fracture Processes in Composite Materials, Springer, Kazimierz Dolny, Poland 2006, 241-248.

[21] K. Ogi, M. Takahashi, S. Yashiro, Polym. Compos. 2011, 32(10), 1652.

[22] L. Farge, Z. Ayadi, J. Varna, Composites Part A: Appl. Sci. Manuf. 2008, 39(8), 1245.

[23] L. Farge, J. Varna, Z. Ayadi, Compos. Sci. Technol. 2010, 70(1), 94.

[24] T. Sebaey, J. Costa, P. Maimí, Y. Batista, N. Blanco, J. Mayugo, Composites Part B: Eng. 2014, 65, 40.

[25] R. Moore, D. Dillard, Compos. Sci. Technol. 1990, 39(1), 1.

[26] J. Raghavan, M. Meshii, Composites Part A: Appl. Sci. Manuf. 1996, 27(12), 1223.

[27] T. H. Nguyen, D. Gamby, Compos. Sci. Technol. 2007, 67(3), 438.

[28] T. Lisle, C. Bouvet, M.-L. Pastor, P. Margueres, R. P. Corral, Composites Part A: Appl. Sci. Manuf. 2013, 53, 75-87.

[29] T. Lisle, C. Bouvet, M.-L. Pastor, T. Rouault, P. Margueres, J. Mater. Sci. 2015, 50(18), 6154.

[30] G. Battams, J. Dulieu-Barton, Composites Part A: Appl. Sci. Manuf. 2016, 91, 420.

[31] R. Fruehmann, J. Dulieu-Barton, S. Quinn, Exp. Mech. 2010, 50(7), 1075.

[32] L. Bodelot, L. Sabatier, E. Charkaluk, P. Dufrénoy, Mater. Sci. Eng.: A 2009, 501(1), 52.

[33] S. Sambasivam, Ph.D. Thesis, University of Southampton, Southampton 2009.

[34] J. Berthe, G. Portemont, A. Deudon, in Comptest 2017, KU Leuven, Leuven 2017, 1-2.

[35] C. Meola, G. M. Carlomagno, Appl. Phys. A 2009, 96(3), 759. 
[36] J.-M. Berthelot, Appl. Mech. Rev. 2003, 56(1), 111.

[37] C. Huchette, Ph.D. Thesis, Université Paris 6, Paris, 2005.

[38] J. Tong, F. Guild, S. Ogin, P. Smith, Compos. Sci. Technol. 1997, 57(11), 1527.

[39] J. Berthe, M. Brieu, E. Deletombe, G. Portemont, Mater. Des. (1980-2015) 2014, 62, 241. 